\title{
Acidity and Dental Erosion from Apple- and Grape-Juice (An in vitro and in vivo Report)
}

\section{Louis ZG Touyz* and Leonardo M Nassani}

McGill University, Canada

*Corresponding author: Louis ZG Touyz, Professor, McGill University, Canada

\begin{abstract}
Introduction: Dental erosion from acid drinks is known; in vitro with in vivo evidence that apple and grape juices cause erosion is rare.

Aim: i) To test acidity ( $\mathrm{pH}$ and buffering capacity) in vitro; ii) And assess if these juices leach calcium from teeth in vivo.

Methodology: First: Six commercially available potable apple and grape juices were measured (six times each drink) for $\mathrm{pH}$ and buffering using $0.5 \mathrm{Molar} \mathrm{NaOH}$ with a Mettler DL 25 Automatic Titrator. The apple and grape juices were measured separately, using a $50 \mathrm{~mL}$ bolus for measures, 6 times for each. Second: Two volunteer cohorts; (One fully dentate WITH TEETH (mean age 20, M:F 6:6, $n=12$ ) the second edentulous WITHOUT TEETH (mean age 61, $M: F \quad 6: 6, n=12$ ), were used to swish with $50 \mathrm{~mL}$ aliquots of Apple and/or Grape juices for 30 seconds. Each sample was analyzed six times with Inductively Coupled Plasma with Optical Emission Spectroscopy (ICP-OES) for Calcium, and Phosphorous. Juices from source were analyzed for Calcium, and Phosphorous, and post-swish expectorate samples were analyzed for Calcium and Phosphorous. Data were analyzed 'blind' by technicians unaware of the source of procured samples.
\end{abstract}

Results: Analysis reveals apple and grape juices have $\mathrm{pH}$ below 5.5. Statistics consistently show significant $(p<0.01$ Student-t paired data) increases in Calcium and Phosphorous leeched from dentate (WITH TEETH) subjects after swishing with apple and grape juices tested. Results provide strong evidence that rinsing with Apple or Grape juices will erode teeth. Grape is more erosive than apple juice.

Conclusion: Apple and grape juices have acidity below critical $\mathrm{pH}$ 5.5; Both have strong buffering capacities and will decalcify teeth by erosion, when exposed to these drinks in diets.

\section{Keywords}

Acid, Apple juice, Buffering, Calcium, Dental-erosion, Drinks, Critical pH, Grape juice, Hydroxyapatite, Phosphorous, Tooth destruction

\section{Introduction}

Acidic drinks and food are consumed worldwide for a long time and presumed to be innocuous to good health and teeth [1]. Acidic drinks and food do affect teeth, and chronic repeated regular consumption exposure will contribute to the causes of dental ravages (in the form of dental abrasion, attrition, erosion and caries) [2]. Acids are sourced in the drinks, but also after drinking them, more acid is produced from oral bacterial plaques catabolizing mono- and disaccharides as fermentable sugars in the drinks [3]. Intra-orally, whole stimulated human saliva slowly neutralizes and/or buffers ingested acid beverages [3,4]. After swallowing a bolus of acid beverage, the intra-oral acidity $(\mathrm{pH}=7.00)$ drops to $\mathrm{pH}=4$ or lower, within 3 to 5 minutes [4]. Oral biofilm with acidogenic bacterial action on fermentable carbohydrates (monosaccharides like glucose and fructose; Disaccharides like maltose and sucrose) also lower the $\mathrm{pH}$ to below $\mathrm{pH}=4$. Intra-oral $\mathrm{pH}$ takes about 25 to 30 minutes to eliminate the acid environment, as further stimulated-saliva neutralizes any residual acid [4]. The acknowledged critical $\mathrm{pH}$ to dissolve hydroxyapatite is $\mathrm{pH}=5.5$ [5]. The major Ca-crystal in teeth is hydroxyapatite, which is structurally composed of calcium-deficient carbonated hydroxyapatite. Consequently, the dental hydroxyapatite crystals are more vulnerable to decalcification in acid media [5]. Frequent regular exposure to acidity from drinks modifies intra-oral $\mathrm{pH}$ to below the critical $\mathrm{pH}(\mathrm{pH}=5.5)$. At $\mathrm{pH} 5.5$ chemical dissolution of calcium from dental hydroxyapatite occurs. Keeping the $\mathrm{pH}$ low at $\mathrm{pH},<\mathrm{pH}=5.5$, promotes mordant development of ravages initiated and developing from decalcification. Not only is the acidity and buff- 
ering of drinks themselves important, but also calcium (and phosphate) content are relevant when considering erosive attack from beverages [5]. Long-term regular drinking, timing of consumption, type and quantity of beverage, and method of drinking, are all recognized as having influences on the realization of dental ravages [2]. Fresh fruits are generally associated with well-being, and images of fresh grapes and particularly apples are linked with healthy teeth $[6,7]$. The association of fresh fruit with manufactured juiced products is promoted as "natural" and wholesome. Consequently, global consumption of fruit drinks takes little regard of the effect on teeth, and most people imbibe these fruit drinks to excess and don't believe there is any long-term damage to their dentition. Fruit drinks contain a variety of nutrient chemicals like carbohydrates, vitamins and various amounts of different carboxylic acids, like malic acid in apples and tartaric acid in grape $[2,6,7]$.

Erosion is described as the loss of calcified tooth material, without the effect of bacteria and no cavitation $[8,9]$. Research shows erosion in teeth in vitro and in vivo, occurs when pop-colas are consumed regularly $[10,11]$. While the acidity of some common liquids is known, few in vivo reports record the $\mathrm{pH}$ of commercially potable grape and apple juices, and their oral effects. Some experimental evidence exists to show fruit drinks are erosive to teeth $[1-3,12,13]$, but scant combined (in vitro and in vivo) evidence exists about the erosive acidic nature linked with the effect of drinking specific commercially available apple and grape juices on teeth [14]. Repeated frequent-exposure by dissolving fruit acids like malic (in apple) tartaric acids (in grape) allows for chronic micro-attacks on the hard tooth material, and slow inexorable dissolution of the teeth, resulting in dental erosion $[12,13,15-17]$.

\section{Aim}

This research reports on the acidity as $\mathrm{pH}$, and buffering capacity in vitro of grape and apple juices, and assesses in vivo if these juices leach out calcium from teeth.

\section{Materials and Methods}

This study was divided into two parts:

Part I: Acid properties: Measures of acidity; $\mathrm{pH}$ and buffering capacity.

Part II: Proof-of-principle: Comparison of calcium in drink, after being swished with teeth and without teeth; $\mathrm{M}=$ Molar; ppm = parts per million $(\mathrm{mg} / \mathrm{L}) ; \mathrm{Ca}^{++}=$Calcium ion.

\section{Part I}

Six commercially available potable apple and six commercially available grape juices were measured (six times for each drink) for $\mathrm{pH}$ and buffering using 0.5 $\mathrm{M} \mathrm{NaOH}$ with a Mettler DL 25 Automatic Titrator [15]. These methods are described in researches on other drinks, namely Colas and Guarana-Pop [10,11]. The apple and grape juices were tested for acidity $\mathrm{pH}$ and buffering; A $20 \mathrm{ml}$ bolus from each was measured 24 times. Buffering/neutralizing was measured with $0.5 \mathrm{M}$ solution of Sodium Hydroxide, to assess how much is needed to: 1) Raise the test sample pH one unit; 2) To raise the $\mathrm{pH}$ to 5.5 (critical $\mathrm{pH}$ ); and 3) To raise the $\mathrm{pH}$ to $\mathrm{pH} 7.00$ neutral (close to oral $\mathrm{pH}$ ). Six Apple juices tested were purchased by chance at retail outlets. The Six different Apple juices were: Tropicana Apple Juice, Minute Maid Apple Juice, Oasis Apple Juice, Oasis Low Acid Apple Juice, Rougemont Apple Juice, and Selection Apple Juice. Six Grape juices tested were purchased by chance at retail outlets. The Six different Grape juices were: Tropicana Grape Juice, Oasis Grape Juice, Welsh's Grape Juice, Rougemont Grape Juice, Fruite Grape Juice and Selection Grape Juice.

Results: For Part I Apple juices Figure 1 and Figure 2, and for Part I Grape juices Figure 3 and Figure 4.

\section{Part II}

Two volunteer cohorts; (One fully dentate (mean age 20; Range 19-22 yrs; $M: F 6: 6, n=12$ ) the second edentulous (mean age 61; Range 55-64 yrs, M:F 6:6, $n$ $=12)$ ), were used. A pilot study with one of the drinks

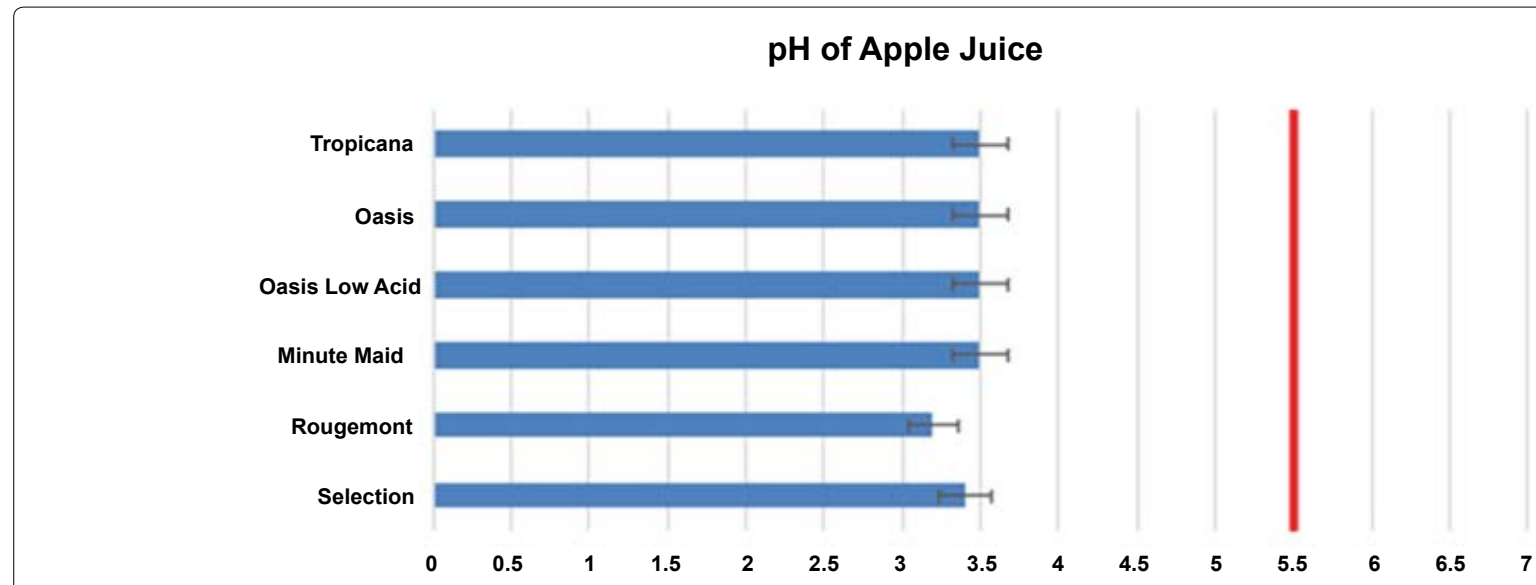

Figure 1: The $\mathrm{pH}$ values of apple juices. Means are recorded: I-bars represent \pm SD. The $\mathrm{pH}$ 's are all below the critical $\mathrm{pH}$ 5.5. (Red vertical line). 


\section{Buffering of Apple Juices to raise one $\mathrm{pH}$ unit, to $\mathrm{pH} 5.5 \& \mathrm{pH} 7$}

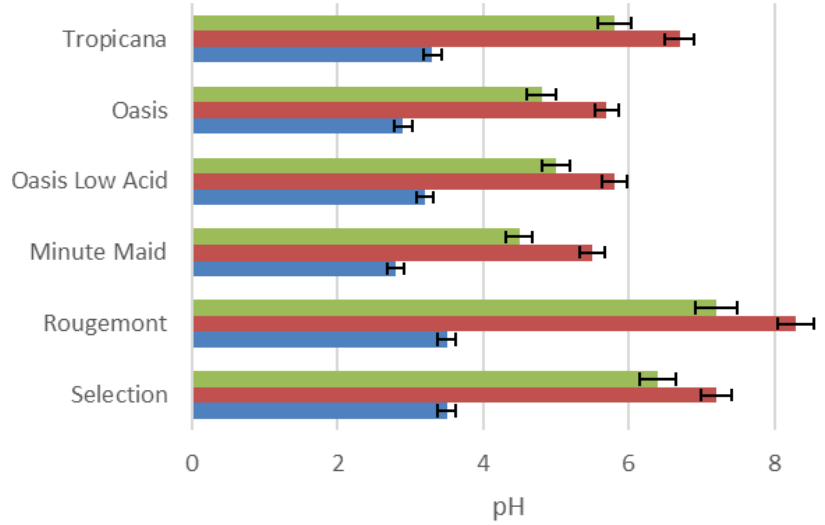

Euffering capacities $(\mathrm{mL})$ for a $\mathrm{pH}$ change up to $\mathrm{pH} 5.5$

- Buffering capacities $(\mathrm{mL})$ for a $\mathrm{pH}$ change up to $\mathrm{pH} 7.0$

- Buffering capacities ( $\mathrm{mL}$ ) for initial $1 \mathrm{pH}$ unit change

Figure 2: The buffering capacity for apple drinks. The mean amounts of 0.5 Molar $\mathrm{NaOH}$ to raise the pH of 6 apple drinks to $\mathrm{pH} 5.5$ (green), to $\mathrm{pH} 7$ (red), and to one $\mathrm{pH}$ unit (blue). I-bars represent $\pm \mathrm{SD}$.

Figure 3 the mean $\mathrm{pH}$ value of grape juices
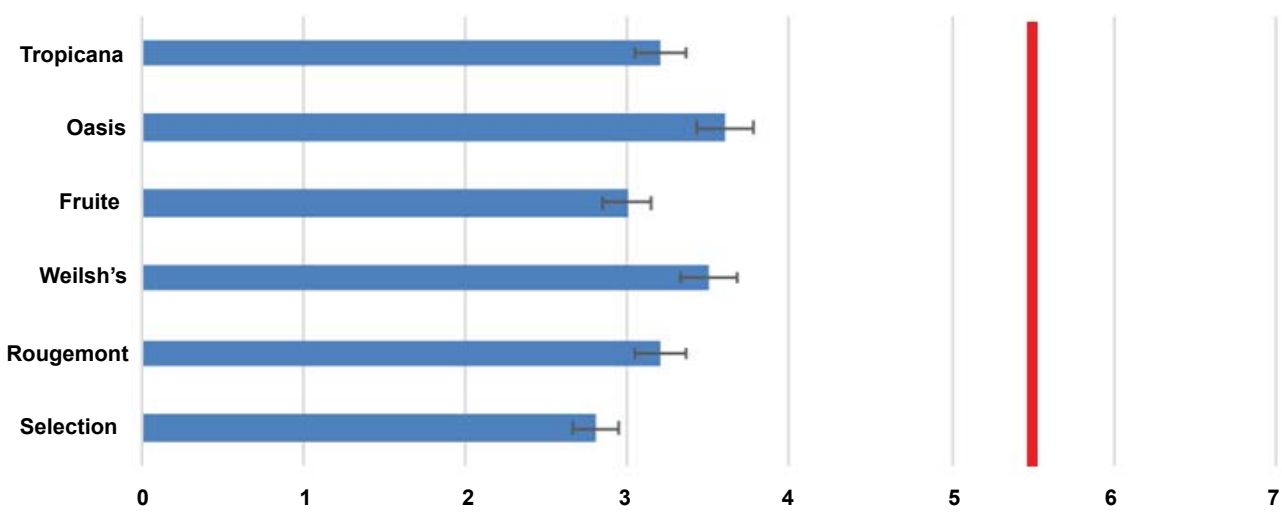

Figure 3: The mean $\mathrm{pH}$ values of grape drinks. I-bars represent $\pm \mathrm{SD}$. They are all below the critical $\mathrm{pH}$ 5.5. (Red vertical line).

\section{Buffering of Grape Juices to raise one $\mathrm{pH}$ unit, to $\mathrm{pH}$ \\ $5.5 \& \mathrm{pH} 7$}
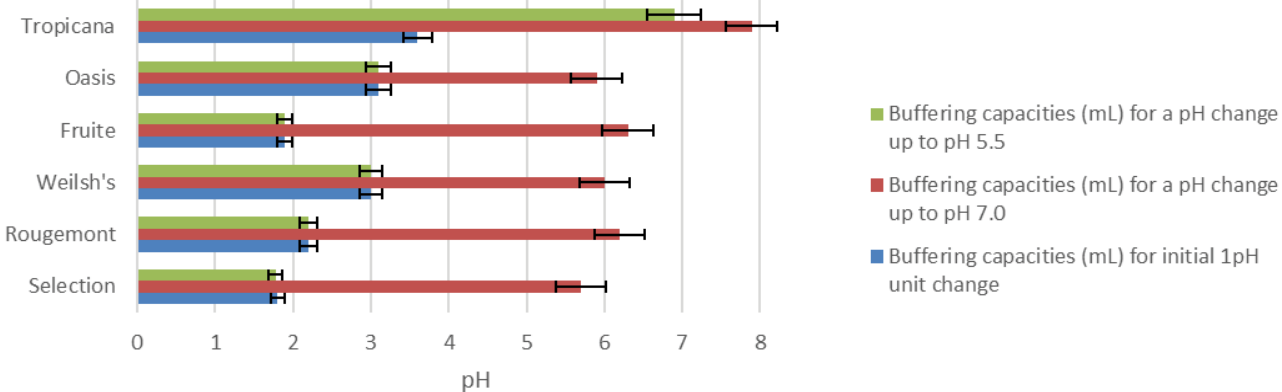

Figure 4: The buffering capacity for grape juices. The mean ( $\pm \mathrm{SD}$ too small) amounts of $0.5 \mathrm{Molar} \mathrm{NaOH}$ to raise the $\mathrm{pH}$ of grape drinks to $\mathrm{pH} 5.5$ (green), to $\mathrm{pH} 7$ (red), and to one $\mathrm{pH}$ unit (blue). I-bars represent \pm SD.

(Tropicana as representative of the brands tested), was performed to establish smooth running, timing, organization and protocol of procedures. Then arrangements were made to test all the brands of both types of drinks by intra-oral swishing for both cohorts. The temperature of all the drinks were $20^{\circ} \mathrm{C}$ (and the room temperature was $23.2^{\circ} \mathrm{C}$ ). First $50 \mathrm{~mL}$ aliquots of one brand of Apple drink was swished for 30 seconds. After expectorating the test sample, a wait time was sustained for 30 minutes and the subject asked to chew some wax, and rinse out with water, for a few seconds before repeating the swish experiment on the next brand of apple drink. Six brands of apple drink were tested. The tests were done succedaneous for each brand; The tests were done six times (one test for each brand of drink) with each subject. Second the same protocol was done by the same 


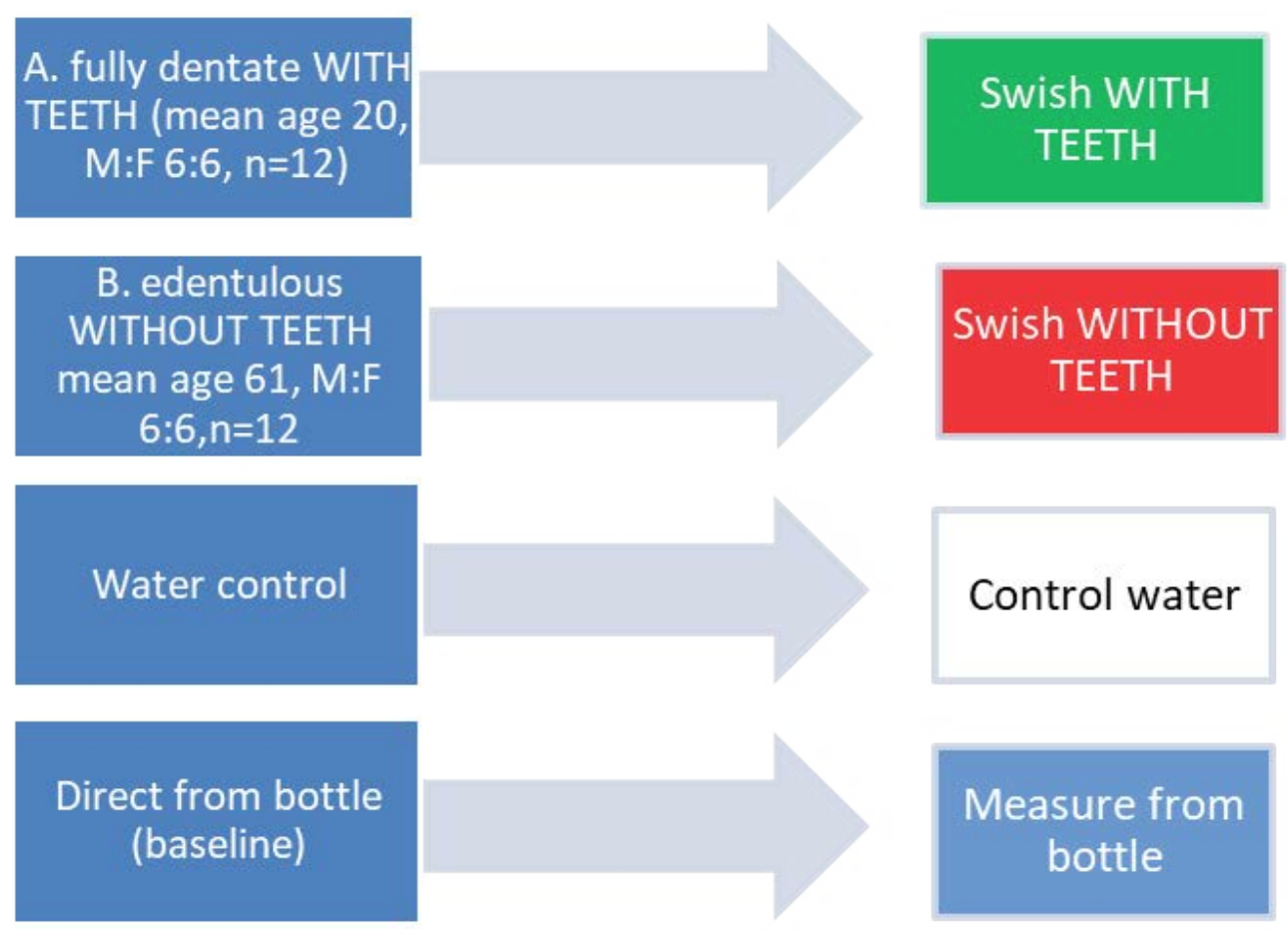

Figure 5: Experimental design for Part II. The drinks were swished by dentate volunteers WITH TEETH (A) and edentulous WITHOUT TEETH (B). The major variable was the presence of teeth in the mouth. Control measures were used for comparison derived from water, and the apple and grape drinks tested.

\section{Calcium Analysis Post-Swish from Grape Juices}

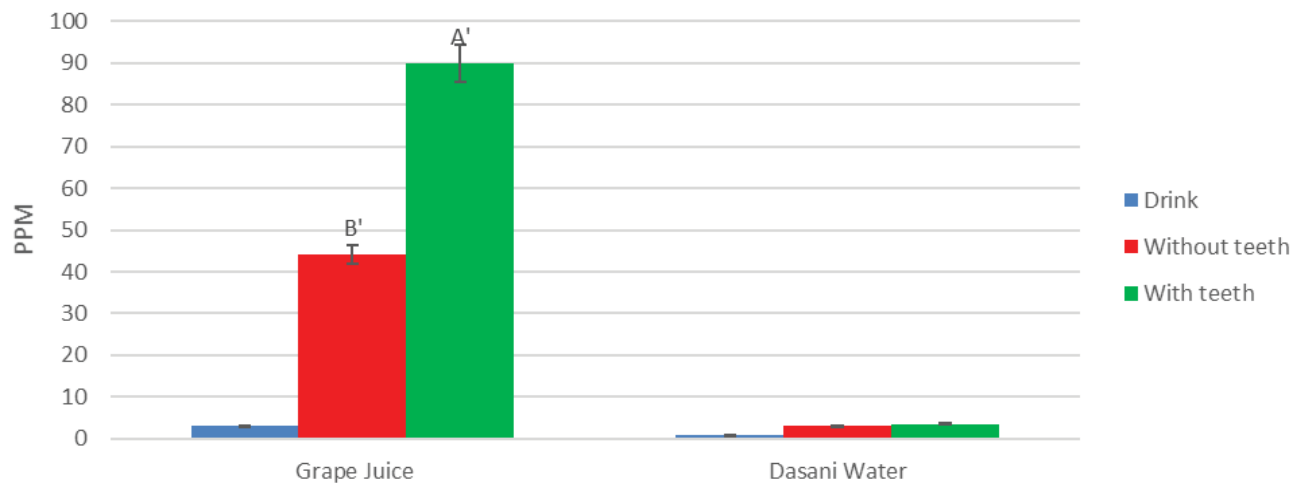

Figure 6: Mean calcium measures direct from the drink can (blue) from grape juice, from swishes WITHOUT TEETH (B') (red), and WITH TEETH (A') (green). The post-swish increase in calcium release is $90 \mathrm{ppm}$ after swishing WITH TEETH, compared to $44 \mathrm{ppm}$ swishing WITHOUT TEETH. There is a highly significant difference when compared to results from dasani bottled water, (0.2-2.5 ppm). Negligible calcium was detected in grape juices from the containers $(0.5 \mathrm{ppm})$. Even when accounting for the $\mathrm{Ca}^{++}$in water stimulated saliva, there is significant $(\mathrm{p}<0.01$ student-t paired data) increases in calcium leeched from the group WITH TEETH, compared to the controls WITHOUT TEETH, after swishing with grape juices. Means are reported ( \pm SD are shown on graphs and were included in statistical analysis).

cohorts, one week apart using six brands of grape drinks. All the experiments were done in one four-hour session, at the same time, (a.m.). On different days, for the dentate and for the edentulous group. The test samples were analyzed the same day they were obtained. " $n$ " for the dentate (WITH TEETH) subjects was $12 \times 6=72$ for the grape and similarly 72 for the apple drinks; " $n$ " for the edentulous (WITHOUT TEETH) group was $12 \times 6$ $=72$. Each swish-test drink was sampled and analyzed six times to procure mean results, with Inductively Coupled Plasma with Optical Emission Spectroscopy (ICPOES) for Calcium, and Phosphorous [10,14,15]. Juices from source were analyzed for Calcium, and post-swish samples were analyzed for Calcium. To avoid inter- and intra-operator bias, all readings, results and data were analyzed 'blind' by technicians unaware of the source of the samples being tested, or the aims of this study (Figure 5).

\section{Measures for Calcium each drink:}

1. Calcium from Swish WITH TEETH A. $A-(D+$ $E)=A^{\prime}$

2. Calcium from swish WITHOUT TEETH.........B. B - (D + $\mathrm{E})=\mathrm{B}^{\prime}$ 
3. Calcium from water C.

4. Calcium from the can ..D.

5. Calcium from stimulated saliva. .E.

Statistics: Compared with paired data from $A^{\prime}$ and B were calculated. $A^{\prime}$ (drink swished WITH TEETH) has significantly more calcium derived from teeth, than B' (drink swished WITHOUT TEETH). $p<0.05$ considered significant. Student-t test was used (Figure 6 and Figure 7).

Results: For Part II Calcium $\left(\mathrm{Ca}^{++}\right)$content, of apple and grape drink-swishes from WITH- and WITHOUT teeth, and with controls using water and measures from the bottle or can. All measures WITH TEETH for calcium showed a significant $(p<0.01)$ increase in Calcium content (Figure 6, Figure 7 and Figure 8).

Further analysis of the results shows significant increases $(p \leq 0.01)$ in leeched calcium from dentate subjects after swishing with the drinks tested. Means are reported $( \pm$ SD are shown on graphs and were included in statistical analysis). Even when accounting for the $\mathrm{Ca}^{++}$derived from saliva-water swishing, statistics consistently show significant $(p \leq 0.01)$ increases in calcium leeched from dentate (WITH TEETH) subjects, compared to edentulous (WITHOUT TEETH) subjects, after swishing with the drinks tested. The grape juices tested caused more decalcification than the apple juices tested (90 ppm Calcium for grape vs. 65 ppm Calcium for apple). Hard tissue erosion, (as chemical dissolution of calcium without bacterial action or cavitation) [18], varies between apple and grape juices, grape causing more erosion. Decalcification was consistently produced from both types of drinks after swishing.

\section{Discussion}

Hard tissue erosion, (as chemical dissolution of calcium without bacterial action or cavitation) [18], varies between apple and grape juices, grape causing stronger

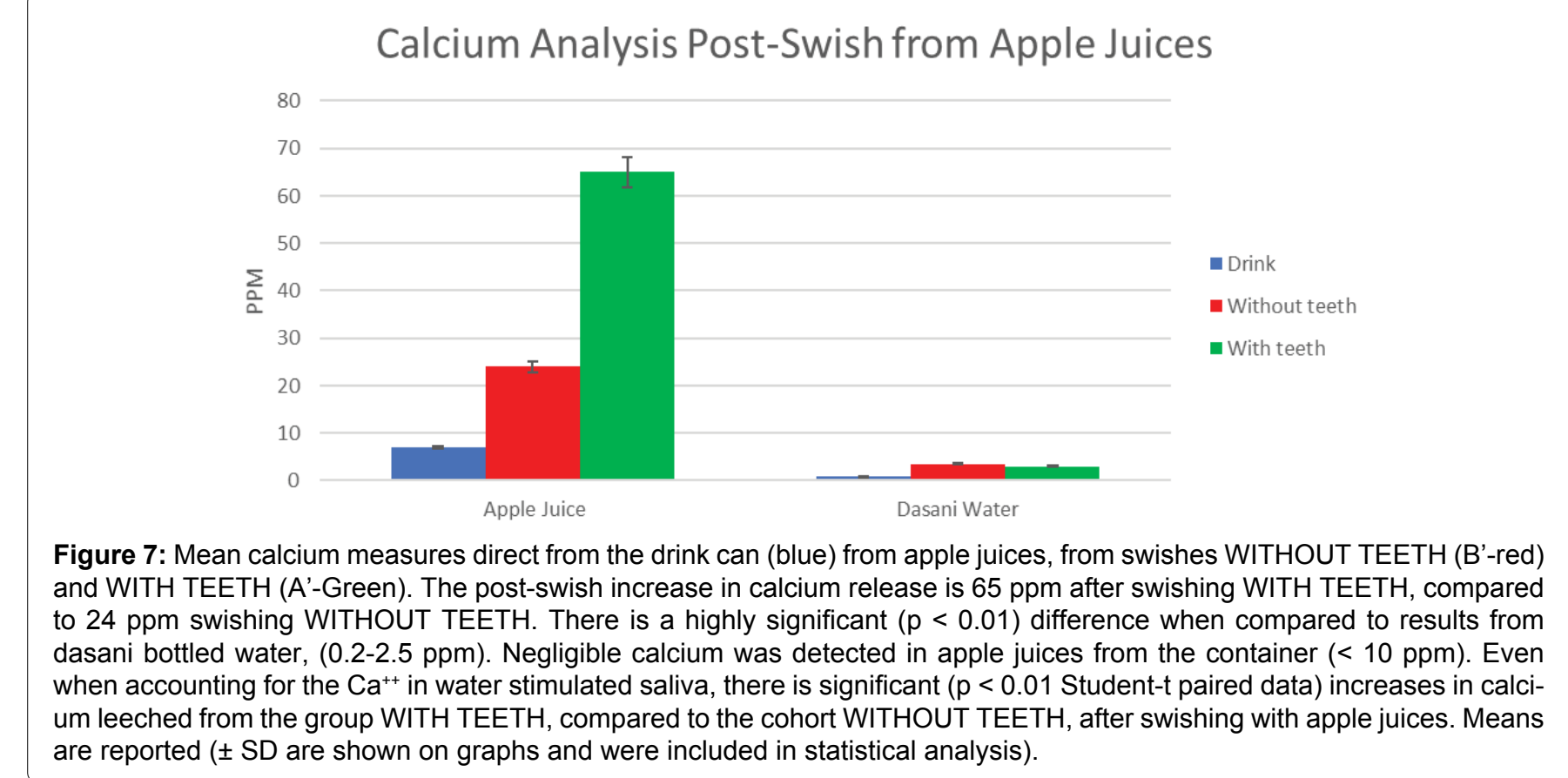
are reported ( \pm SD are shown on graphs and were included in statistical analysis).

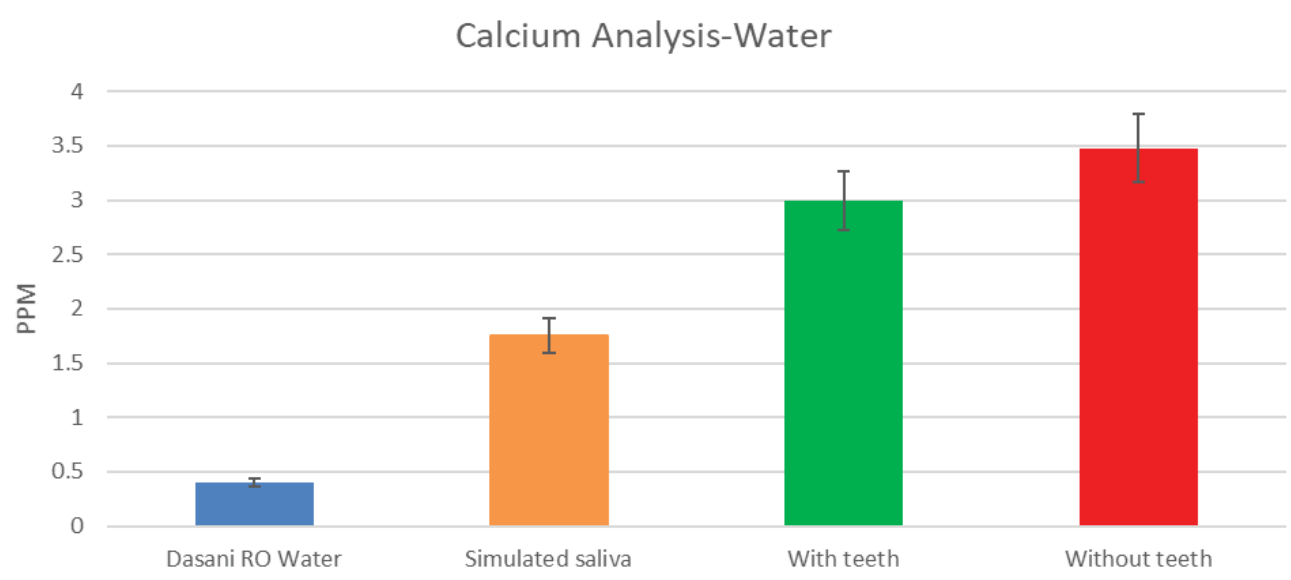

Figure 8: Mean calcium measures of dasani bottled water as control (blue). To start $0.5 \mathrm{ppm} \mathrm{Ca}^{++}$is found to start from the container, and $2.5 \mathrm{mg} \mathrm{Ca}^{++}$(maximum) from stimulated saliva (orange). This increases up to 3-3.5 ppm Ca ${ }^{++}$both WITH TEETH (green) and WITHOUT TEETH (red); These increments are extremely small. This small amount of calcium is derived from both dental and saliva. This is accounted for and used for comparisons as the baseline control. I-bars represent \pm SD. 


\section{pH Values of Various Liquids Compared to Apple and Grape Juices}

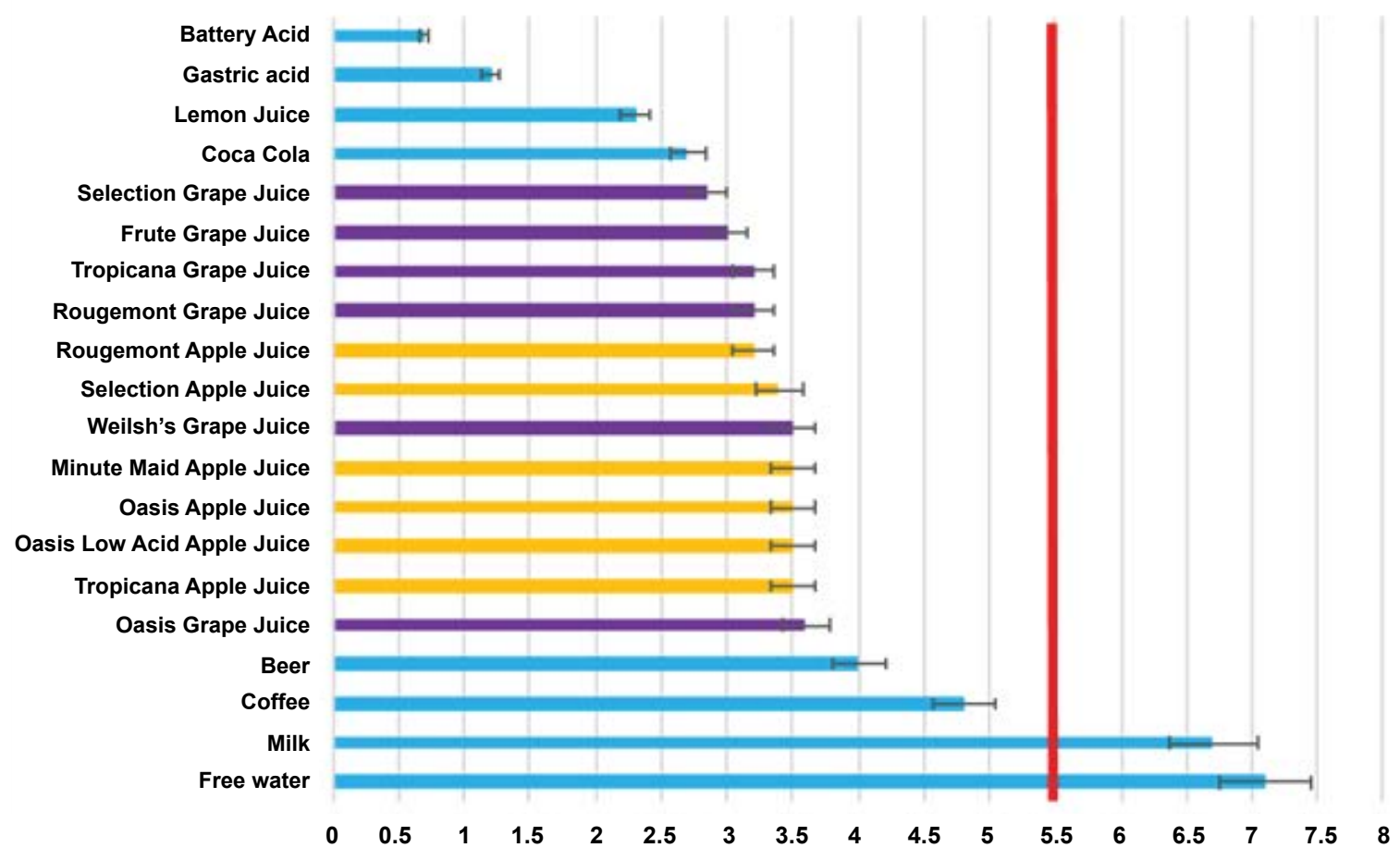

Figure 9: $\mathrm{pH}$ measures of ubiquitous acid liquids: The blue bars are $\mathrm{pH}$ measures of other common liquids. All the acidities of the grape and apple juices measure $\mathrm{pH} 3.5$ (purple and yellow bars in this graph) and are significantly below the critical pH 5.5 (red vertical line) at which pH most acids dissolve calcium hydroxyapatite in teeth.

erosion. Decalcification was consistently produced from both types of drinks after swishing. The results of this research are in concordance with other related researchers, that show powdered and other modified acid drinks are erosive $[13,16,19]$. In the research presented above, the acidity as measured by $\mathrm{pH}$ and buffering capacity of the drinks was all significantly lower than the critical $\mathrm{pH}$ 5.5. This indicates these acid drinks have the strong potential to dissolve calcium out of teeth. It also suggests saliva which is a weaker alkali than $0.5 \mathrm{Molar} \mathrm{NaOH}$, does not quickly nor totally neutralize imbibed acid. Some authorities $[6,7,18]$. State the intra-oral recovery period back to neutral takes 30 minutes without further salivary stimulus, that the critical $\mathrm{pH}$ is 6.5 , and with a physical stimulus like from a bland wax-chew, the stimulated saliva hastens neutralizing the residual dietary acid $[6,7,18]$. Compared to other common ubiquitous liquids, the apple and grape juices as tested were recorded at a $\mathrm{pH} 3.5$, which is very acidic with strong buffering capacity, and consequent erosive effects (Figure 9).

Dental erosion may be moderated by various co-factors including dental substrate density, $\mathrm{Ca}^{++}$, phosphate $\left(\mathrm{PO}_{4}\right)^{3-}$, and fluoride $\left(\mathrm{F}^{-}\right)$composition. The phosphate concentration is not reported here as it does not add to the evidence demonstrating proof-of-principle of decalcification. Also, the enamel pellicle, salivary proteins, volume of stimulated saliva, dental anatomy, occlusion (as it influences flow over tooth surfaces), vigorous function of oral soft tissues especially the tongue, ... all may affect development of erosion $[4,5,7,18]$. But none are as important as the decalcification by acid action, notably the composition, and the measure of acidity: The $\mathrm{pH}$, and buffering capacity of the drinks. As shown above, apple and grape are no exception to this. Because it is virtually impossible to procure young age-matched edentulous (WITHOUT TEETH) people as controls, the age difference in the edentulous controls was accepted, as the edentulous cohort were all healthy, and not taking any medications. The dentate (WITH TEETH) test-subjects were also all healthy, and an oral visual examination confirmed they all had a full complement of well-formed, erupted functional adult teeth, and wisdom teeth (if present) were accepted, but were not mandatory. DMFT (decayed missing and filled teeth index) was ignored. The controls as measures of the calcium $\left(\mathrm{Ca}^{++}\right.$) reported (and phosphate $\left(\mathrm{PO}_{4}\right)^{3-}$ ) ions, not reported here) direct from the cans, and after water-swishing were small. When subtracting this from results derived after test-swishing, statistics consistently show significant $(p \leq 0.01)$ increases in Calcium leeched from dentate (WITH TEETH) subjects, compared to edentulous (WITHOUT TEETH). Rationally, the extra calcium in the swished-expectorates, could only derive from the teeth. Colas and other similarly acidic gaseous drinks containing phosphoric and citric acids, with or without sugars added, show similar results $[10,11]$. Because the buffering capacity of saliva is weak neutralization will take up to half an hour to neutralize the residual oral acidity, and to return the intra-oral $\mathrm{pH}$ to baseline $\mathrm{pH} 7[4,18]$. The reasoning behind using 30 secs swishing with $50 \mathrm{~mL}$ aliquots is as follows: Aliquots 
of $50 \mathrm{mls}$ were swished for 30 seconds. A $350 \mathrm{ml}$ can of drink takes about seven gulps to finish, and each gulp is in the mouth with each mouthful in contact with teeth, for about 4 to 5 seconds. Most drinkers finish a 350 $\mathrm{ml}$ can within a period of 5 to 10 minutes. With seven gulps of $50 \mathrm{ml}$ to finish a can of the drink, amounts to the equivalent of swishing a $50 \mathrm{ml}$ bolus for about 30 seconds. During this time, the intra-oral acid drink will be in contact with the teeth-surfaces. This explains why 30 seconds of swishing was used for the in vivo testing. The intra-oral $\mathrm{pH}$ allows for decalcification during this period. Clinically, among the earliest signs of erosion is the onset of cervical dentinal sensitivity [20]. When this is reported further investigation and advice on reduced dietary intake of acidulated drinks is indicated [12]. Further comparisons between other potable acidic drinks call for further in vivo research.

\section{Concluding Remarks}

With regard to apple and grape juices, both contain known carboxylic acids, malic in apple, tartaric in grape. Both drinks, as apple or grape juices in a diet, may cause dental erosion. Grape seems to be more erosive than apple juices. Constituent apple (malic) and grape (tartaric) acids overwhelms all the co-factors of oral protective mechanisms in vivo and allows dental decalcification. The erosion may be small and undetectable with solitary drinking, but results presented here provide strong evidence that prolonged and frequent imbibing of apple and grape juices will erode teeth.

\section{Authors Statement}

The authors have no conflict of interests to declare.

\section{Ethics}

This research was approved by McGill Human Ethics Internal Review Board: Reference Number: AO2-M31-088. Informed consent forms, privacy and all requirements were satisfied, complied with and instituted for this project.

\section{Funding}

This research was supported by a grant (OVPR-217 000) from the Office of the Vice-Principle Research, McGill University.

\section{Acknowledgements}

Thanks to Prof. Richard Munz, Dr. Natalie Tufenkji, Andrew Golsztain ${ }^{* *}$, Ranjan Roy ${ }^{* *}$, McGill University Faculty of Dentistry, ${ }^{* *}$ Dept of Chemical Engineering, for providing laboratory space, facility and technical assistance.

\section{References}

1. Bawa S (2005) The role of the consumption of beverages in the obesity epidemic. J R Soc Health 125: 124-128.

2. Touyz LZG, Mehio A (2006) Dental ravages from acidulated soft drinks: A review. Aesthetic \& Implant Dentistry 8: 20-33.
3. Johansson AK, Lingström P, Imfeld T, Birkhed D (2004) Influence of drinking method on tooth-surface $\mathrm{pH}$ in relation to dental erosion. Eur J Oral Sci 112: 484-489.

4. Dawes C (2003) What is the critical pH and why does a tooth dissolve in acid? J Can Dent Assoc 69: 722-724.

5. Featherstone JD, Lussi A (2006) Understanding the chemistry of dental erosion. Monogr Oral Sci 20: 66-67.

6. Touyz LZG (1980) Apples acid and teeth. SAJ Sci 76: 200201.

7. Touyz LZG (2016) Demystifying apples in health and dentistry. Dent Health Curr Res 2.

8. Touyz LZG (1983) The initiation of the effect of commercially prepared dried apple on dental caries in albino rats. Arch Oral Biol 28: 369-370.

9. Touyz LZG, Glassman RM, Naidu S (1981) Erosive action of apple juice and orange juice on rats molars in vivo. SAJ Sci 77: 423-424.

10. Borjian A, Ferrari CIC, Anouf A, Touyz LZG (2010) Pop-cola acids and tooth erosion: An in vitro, in vivo, electron-microscopic and clinical report. International Journal of Dentistry.

11. Ferrari CIC, Touyz LZG (2013) Clinical implications from an in vitro and in vivo investigation of acidity, erosion and pain from common pop-acidulated drinks: Cola and guaraná drink. International Journal of Clinical Dentistry 6: 279-290.

12. Touyz LZG, Silove M (1994) Frozen fruit juices as a potential cause of dental hypersensitivity. Archives of Oral biology 39: S130.

13. Ehlen LA, Marshall T, Qian F, Wefel JS, Warren JJ (2008) Acidic beverages increase the risk of in vitro tooth erosion. Nutr Res 28: 299-303.

14. Lussi A, Jaeggi T (2006) Chemical factors. Monogr Oral Sci 20: $77-87$.

15. Association of official agricultural chemists (AOAC-2018): Calcium and phosphate measurements. Calcium and phosphorous. Association of official agricultural chemists (AOAC) 984.27. Modified method 984.27, ICPOES. Calcium \& phosphorous. ICP-OES METTLER DL25 Titrator.

16. Beltrame APCA, Noschang RAT, Lacerda DP, Souza LC, Almeida ICS (2017) Are grape juices more erosive than orange juices? Eur Arch Paediatr Dent 18: 263-270.

17. Gonçalves GKM, Guglielmi CAB, Corrêa FNP, Raggio DP, Corrêa MSNP (2012) Erosive potential of different types of grape juices. Braz Oral Res 26: 457-463.

18. Imfeld T (1996) Dental erosion, definition, classification and links. Eur J Oral Sci 104: 151-155.

19. Sales-Peres SHC, Magalhães AC, Machado MAAM, Buzalaf MAR (2007) Evaluation of the erosive potential of soft drinks. Eur J Dent 1: 10-13.

20. Touyz LZG (1983) Fruit induced sensitivity at cervical margins. JASA 38: 199-200. 